\title{
Parâmetros nutricionais em bovinos de corte: Revisão sobre consumo, digestibilidade e conversão alimentar
}

\author{
Rodrigo da Silva Lima ${ }^{1 *}$, José Almir Ferreira Gomes ${ }^{1}$, Edmilson Gomes da Silva ${ }^{1}$, Thiciano Leão \\ Miranda ${ }^{1}$, Rafael Santos de Aquino ${ }^{2}$, Almir Ferreira da Silva ${ }^{3}$ \\ ${ }^{1}$ Professores do Instituto Federal de Educação, Ciência e Tecnologia do Sertão Pernambucano/Campus \\ Salgueiro. \\ ${ }^{2}$ Professor do Instituto Federal de Educação, Ciência e Tecnologia do Sertão Pernambucano/Campus Ouricuri; \\ ${ }^{3}$ Zootecnista. \\ *Autor para correspondência, E-mail: rodrigo.lima@ifsertao-pe.edu.br
}

\begin{abstract}
RESUMO. Este trabalho foi desenvolvido com o objetivo de revisar na literatura quais são os principais fatores que interferem nas características consumo alimentar, digestibilidade dos alimentos e nutrientes e na conversão alimentar de bovinos de corte nos trópicos. Essas características foram escolhidas para estudo por serem extremamente importantes para obtenção de bom desempenho em ganho em peso. A pecuária de corte brasileira é uma atividade caracterizada pela produção a pasto, permitindo grande variação nessas características entre rebanhos e regiões. Assim, torna-se necessário compreendê-las para influenciá-las a permitirem um crescimento corporal mais rápido e obtenção de animais mais precoces, o que proporcionará maior lucratividade a cadeia produtiva da carne bovina.
\end{abstract}

Palavras chave: Alimentação, ganho em peso, pastagens

\section{Nutritional parameters in beef cattle: A review of intake, digestibility and feed conversion}

\begin{abstract}
This work was developed with the objective of reviewing the literature which are the main factors affecting the characteristics feed intake, digestibility of nutrients and food and feed efficiency of beef cattle in the tropics. These characteristics were chosen for study because they are extremely important for achieving good performance in weight gain. Livestock Brazilian cut is an activity characterized by grass production, allowing great variation in these characteristics among herds and regions. Thus, it is necessary to understand them to influence them to allow a more rapid body grow than getting more precocious animals, which provide greater profitability in the beef production chain.
\end{abstract}

Key-words: feeding, weight gain, pastures.

\section{Introdução}

O Brasil possui o maior rebanho bovino do mundo, o que confere um grande potencial na exploração da pecuária de corte brasileira (FAPRI, 2015). Contudo, o sistema produtivo predominantemente utilizado é a produção a pasto, formado, em sua maioria, por espécies forrageiras de clima tropical (Ferraz \& Felício, 2010). Essas espécies são caracterizadas pela baixa qualidade nutricional, sobre tudo, com elevada quantidade de conteúdo fibroso principalmente na estação seca do ano, quando comparadas com espécies de clima temperado
(Moreira et al., 2004). Assim, em muitos casos, essa baixa qualidade nutricional causa significativa diminuição na digestibilidade dos nutrientes e, consequentemente, também diminuição no consumo de matéria seca, acarretando em piores índices de conversão alimentar e menor desempenho animal. Assim, o objetivo deste trabalho é contextualizar o conhecimento a respeito do consumo de matéria seca, da digestibilidade aparente dos nutrientes e entender como modificações nesses parâmetros alteram a conversão alimentar em bovinos de corte. 


\section{Consumo}

O consumo de matéria seca é um dos principais fatores que interferem na produção animal. De acordo com Mertens (1994), dentre os vários fatores que podem interferir no desempenho animal, o mais importante é o consumo de matéria seca, pois cerca de $70 \%$ da variação observada na ingestão de energia digestível entre os animais e as dietas está relacionada às diferenças no consumo, sendo que as diferenças na digestibilidade correspondem a somente $30 \%$ dessa variação. Para Van Soest (1994) pelo consumo é possível determinar a quantidade de nutrientes ingeridos e, consequentemente, estimar a produção animal. Assim, o aumento do consumo voluntário tornase importante para que as metas produtivas sejam alcançadas e a lucratividade do sistema seja a máxima possível.

Devido à grande importância que o consumo de matéria seca apresenta, desde algum tempo atrás se busca elaborar equações que tentam predizer o consumo pelo animal. Segundo o NRC (2000) os fatores que regulam o consumo nos animais ruminantes ainda não são totalmente compreendidos. No entanto, uma predição acurada do consumo de matéria seca é fundamental na formulação de dietas para que desta forma se consiga atender as exigências nutricionais, assim como predizer o ganho em peso diário dos animais e estimar a lucratividade do sistema produtivo.

Os pontos críticos para se estimar o consumo são as limitações relativas entre o animal, o alimento e as condições de alimentação (Mertens, 1994). Assim, a estimativa do consumo torna-se passível a imprecisões devido aos vários fatores que podem interferir.

Para Silva et al. (2002) para que os animais ruminantes atinjam produções máximas estipuladas pela capacidade genética, precisam consumir quantidades suficientes de energia, proteína, minerais e algumas vitaminas, não se esquecendo da estrutura física dos alimentos que deve ser considerada quando se deseja otimizar o aproveitamento de uma ração.

O consumo de alimentos pelos ruminantes pode ser regulado por diversos mecanismos, por esta razão, o tamanho, a condição corporal, a capacidade de distensão ruminal, a raça e o "status" fisiológico são características que influenciam o consumo, pois alteram os requerimentos dos animais (Pereira et al. 2006). Ainda para esses mesmos autores, devido à importância que o consumo apresenta na produção animal, justifica-se a existência e o contínuo surgimento de numerosos estudos que objetivaram comprovar hipóteses a respeito dos mecanismos de regulação do consumo voluntário.

Segundo Mertens (1987), o consumo pelos ruminantes pode ser regulado por três mecanismos: físico, fisiológico e psicogênico. Para Allen (2000), com relação ao mecanismo físico, o consumo voluntário de matéria seca está relacionado com a capacidade de distensão do rúmen-retículo, podendo esse consumo ser limitado nos ruminantes que consomem dietas à base de forragens como resultado de um menor fluxo da digesta através do trato gastrointestinal. Para Van Soest (1994) a fibra em detergente neutro (FDN) é um fator dietético bastante representativo do volume ocupado pelo alimento e dietas com elevada proporção de fração fibrosa preenche os espaços do rúmen-retículo, levando maior tempo do que o conteúdo celular para deixar este compartimento.

Os constituintes moleculares que compõem a FDN possuem digestibilidade menor do que os constituintes intracelulares. Essa é uma característica promovida pelos arranjos e ligações moleculares dos carboidratos e compostos fenólicos que compõem a parede celular das células vegetais, ou seja, a fração FDN. Devido a essa menor velocidade na digestão da fração fibrosa, os alimentos mais ricos nessa fração necessitam passar mais tempo sofrendo a ação degradativa dos microrganismos ruminais para poderem atingir um tamanho de partícula que consiga ser carreada para o trato gastrointestinal posterior.

Já com relação ao mecanismo de regulação fisiológico, de acordo com Mertens (1997), a regulação do consumo é dada pelo balanço nutricional ou status energético. Geralmente, a densidade energética de uma dieta é calculada de acordo com as exigências de manutenção e produção. Sendo assim, a ingestão energética é igual ao requerimento animal. Com isso, se percebe a importância de se oferecer ao animal uma dieta com adequada densidade energética, para que a ingestão de energia não seja limitada pelo efeito do enchimento como em casos de dietas muito fibrosas que podem levar a uma diminuição da produção animal. Assim, muito 
provavelmente o consumo de matéria seca seria menor do que aquele predito baseado na teoria do controle físico. Para Illius \& Jessop (1996), em condições em que o consumo não seja limitado pelo efeito do enchimento, este é mais provavelmente determinado por reações metabólicas relacionadas à habilidade que o organismo animal possui em utilizar os nutrientes absorvidos. Esses nutrientes irão desencadear reações hormonais para regular o consumo.

Em dietas com elevada densidade calórica, a saciedade seria um fator limitante do consumo (Cabral et al., 2006), sendo que neste caso, as exigências do animal controlariam o consumo tais como em condições de animais em confinamento.

Já o mecanismo psicogênico envolve respostas no comportamento do animal devido a fatores inibidores ou estimuladores relacionados ao alimento ou ao ambiente que não são relacionados à energia ou enchimento da dieta. Fatores como sabor, odor, textura, aparência visual de um alimento, status emocional do animal, interações sociais e o aprendizado podem modificar a intensidade do consumo de um alimento (Mertens, 1994).

Materiais passíveis de serem ingeridos são selecionados por visão e/ou cheiro e a decisão em relação a comer ou não é tomada. Uma vez na boca, o alimento pode ser engolido ou rejeitado, dependendo do seu gosto e textura. Depois de engolir, o animal está comprometido com a digestão, absorção e metabolismo daquele alimento, sendo que, se houver algum desequilíbrio metabólico com a ingestão daquele alimento, o animal, através de sua capacidade de aprendizado, o rejeitará na próxima vez que ele for ofertado, desde que tenha a possibilidade da escolha (Van Soest, 1994).

Assim, devido a importância que o consumo de matéria seca apresenta no desempenho animal, vários trabalhos (Pereira et al., 2006, Souza et al., 2007, McMeniman et al., 2009, Missio et al., 2010, Pinto et al., 2010, Bergamaschine et al., 2011) têm avaliado este parâmetro em animais em confinamento. O que se observa, de maneira geral, é que entre as várias características que podem influenciar o consumo de matéria seca, a relação volumoso/concentrado e a quantidade de FDN nas dietas, parecem ser os fatores que mais interferem na quantidade de alimento consumido pelo animal.

\section{Digestibilidade}

Além do consumo de matéria seca, a digestibilidade também influencia o desempenho por ser um parâmetro que determina quanto dos nutrientes ingeridos serão aproveitados para o metabolismo animal (Zeoula et al., 2006). De acordo com Van Soest (1994), o consumo pode estar correlacionado com a digestão dos nutrientes, dependendo do nível energético da ração, sendo que, com o aumento na digestibilidade ocorre menor consumo em dietas com baixa FDN, enquanto que em dietas com elevada FDN ocorre aumento no consumo com o aumento da digestibilidade.

Possivelmente, nas dietas com baixa FDN (alta energia), ao aumentar a digestibilidade, o consumo estaria sendo limitado pela saciedade energética, enquanto que nas dietas com elevada FDN (baixa energia), onde o enchimento estaria promovendo limitação no consumo, o aumento na digestibilidade reduziria esse efeito, aumentando tanto a taxa de passagem como o consumo.

A estimação da digestibilidade de um alimento constitui aspecto preponderante de acesso ao seu teor energético, notadamente via nutrientes digestíveis totais, permitindo $\mathrm{o}$ balanceamento adequado de dietas que propiciem o atendimento das demandas para mantença e produção dos animais (Detmann et al., 2006, Zeoula et al., 2002).

De acordo com Van Soest (1994), digestibilidade é característica do alimento e indica a porcentagem de cada nutriente de um alimento que o animal pode utilizar, sendo que o efeito associativo entre os alimentos pode modificar a digestibilidade de um ingrediente. Para Van Soest (1994), além do efeito associativo entre os alimentos, a digestão também pode ser influenciada pela composição química das dietas, pela velocidade de degradação dos alimentos no rúmen, pela proporção dietética de proteína e energia e também por características próprias do animal.

Nos ruminantes, a digestão dos nutrientes dietéticos ocorre através de processos de hidrólise ácida e enzimática própria no abomaso e no intestino delgado e por processos fermentativos nos pré-estômagos e no intestino grosso (Russell et al., 1992). Nos compartimentos fermentativos ocorre a digestão da fibra dietética através da ação enzimática 
microbiana, extraindo dos alimentos energia que não poderia ser aproveitada sem a ação degradativa dos microrganismos.

Considerando que não são digeridos no intestino delgado, é desejável que os constituintes fibrosos sejam fermentados no rúmen, produzindo ácidos graxos voláteis e células microbianas, os quais representam a principal fonte de energia e aminoácidos, respectivamente, para o ruminante. Entretanto, alguns fatores podem afetar a digestão ruminal desses compostos, incluindo aqueles relacionados às características físico-químicas da parede celular vegetal, a taxa de passagem da digesta para os intestinos e as variações na microbiota ruminal e nas características físico-químicas do rúmen (Cabral et al., 2006).

Os carboidratos não-fibrosos são extensamente fermentados e é uma fonte de energia imediata para os microrganismos. Já a digestão dos carboidratos fibrosos ocorre de forma mais lenta e fica condicionada as bactérias fermentadoras de carboidratos estruturais que se associam as fibras do alimento e degradam componentes da parede celular das células vegetais, particularmente celulose e hemicelulose. Essas bactérias possuem uma taxa de crescimento relativamente mais lenta que as bactérias que degradam carboidratos não estruturais e dependem de amônia e de ácidos graxos de cadeia ramificada para se multiplicarem.

Desta forma, dietas ricas em conteúdo fibroso necessitam de um aporte adicional de nitrogênio não-protéico, como uréia, para disponibilizar quantidades suficientes de nitrogênio para que haja máxima digestão dos carboidratos fibrosos. No entanto, para Paixão et al. (2006), o nível máximo de inclusão de uréia nas rações e seus efeitos sobre o consumo e a degradabilidade da dieta ainda não estão totalmente definidos.

Outro fator que também interfere na digestibilidade dos alimentos é o $\mathrm{pH}$ ruminal. Geralmente ocorre declínio no $\mathrm{pH}$ com o aumento da quantidade de concentrados fornecidos na dieta. Para Pereira et al. (2006), dietas com maiores níveis de concentrados promovem maior proliferação de microrganismos amilolíticos em detrimento dos celulolíticos e, consequentemente, ocorre menor digestão da fibra.
Em estudo de digestibilidade, Andrade et al. (2002) verificaram uma digestibilidade máxima da matéria seca com 40,9\% de carboidratos nãofibrosos na dieta, com queda acentuada na digestibilidade quando o nível de carboidratos não-fibrosos ultrapassava $43,0 \%$ da matéria seca. Nesse trabalho, os autores afirmaram que a inclusão de palma forrageira na dieta dos animais apresentou efeito similar a adição de concentrados, na digestibilidade da matéria seca, devido à palma forrageira também apresentar elevada quantidade de carboidratos não-fibrosos.

De acordo com Van Soest (1994), além da diminuição do $\mathrm{pH}$ ruminal que ocorre com a ingestão de dietas ricas em carboidratos nãofibrosos, há aumento na taxa de passagem, o que também pode comprometer a digestão dos alimentos.

Aumento na taxa de passagem geralmente ocorre com a inclusão de palma forrageira na dieta que, além de apresentar elevada quantidade de carboidratos não-fibrosos, possui baixos teores de FDN, necessitando (Mattos et al., 2000) estar associada a uma fonte de fibra que apresente alta efetividade física. Andrade et al. (2002) utilizando palma forrageira em substituição ao feno de capim tífton para vacas da raça holandesa, verificaram aumento na frequência de defecação a medida que se incluía palma forrageira na dieta, sendo esse comportamento atribuído ao aumento na taxa de passagem da digesta.

Com o aumento na taxa de passagem, a ação degradativa dos microrganismos ruminais fica limitada devido ao pouco tempo para atuação das enzimas microbianas, reduzindo assim a digestibilidade dos nutrientes no rúmen. Além da baixa efetividade da fibra e da elevada quantidade de carboidratos não-fibrosos, a palma forrageira possui baixo teor de matéria seca (10\%) (Valadares Filho, 2006) o que também contribui para aumento na taxa de passagem, diminuindo a digestibilidade da matéria seca quando não associada a uma fonte de fibra. Já quando associada, a mistura passa mais tempo no rúmen sofrendo a ação degradativa das enzimas microbianas aumentando a digestibilidade e o aproveitamento dos nutrientes.

\section{Conversão alimentar}

A capacidade de consumir e digerir os alimentos são fatores determinantes na produção animal. No entanto, outro fenômeno que também 
apresenta efeito direto na resposta produtiva é a capacidade que o animal apresenta em converter os nutrientes consumidos em produto animal, seja leite, carne, lã, pele, etc. Para Fernandes et al. (2004), a conversão alimentar representa a eficiência que o animal converteu o alimento consumido em carne, se tratando de bovinos de corte, e que é economicamente mais importante a disseminação de material genético capaz de converter mais eficientemente o alimento, o que melhoraria a eficiência produtiva.

Nos sistemas de produção de bovinos de corte se tem utilizado o efeito da heterose para melhorar as características produtivas e, dentre elas, a conversão alimentar. $\mathrm{O}$ índice de conversão alimentar é dado pela quantidade de alimento consumido dividido pela quantidade de produto formado. Este índice geralmente é melhorado com a inclusão de concentrados nas rações, ou seja, com o aumento da densidade energética das dietas. Esse resultado foi verificado por vários trabalhos realizados (Resende et al., 2001, Costa et al., 2005, Baião et al., 2005, Missio et al., 2009, Olveira et al., 2009) concordando que a medida que se aumenta a concentração energética da ração, geralmente através da adição de concentrados, há uma diminuição do índice de conversão alimentar. O que acontece de fato é que quando do aumento de concentrados (desde que bem balanceados) na dieta do animal, todos os nutrientes estarão disponíveis para os processos biossintéticos, seja produção de músculo, gordura, tecido ósseo, etc. No entanto, essa adição de alimentos concentrados na dieta de animais ruminantes deve ser inferior a quantidade a partir da qual há ocorrência de distúrbios ruminais, como, por exemplo, a acidose.

Outra característica que influencia a conversão alimentar em bovinos utilizados para produção de carne é a composição do ganho em peso. Para Fernandes et al. (2004), a eficiência de utilização da energia para ganho em peso é influenciada pela composição corporal, sendo que esta eficiência diminui com o aumento da deposição de gordura na carcaça, devido a menor eficiência de conversão da energia em tecido adiposo em comparação com tecido muscular.

Sendo assim, sabendo que diferentes grupos genéticos possuem velocidade de acabamento de carcaça diferenciada, devido a uma maior ou menor habilidade em depositar gordura, pressupondo-se que ele está diretamente relacionado com a precocidade de terminação, outro fator que poderia ser incluído como uma fonte de variação potencial na conversão alimentar é o grupo genético.

Os estudos já realizados indicam que o consumo, o ganho em peso e a conversão alimentar têm sido diferentes entre os grupos genéticos Bos taurus e Bos indicus (Prado, 2010). No entanto, se deve ter cautela quando se realiza essas comparações, pois o tamanho corporal, assim como a fase de desenvolvimento, entre outros fatores interferem na eficiência de utilização dos nutrientes ingeridos. É conhecido também que bovinos de maior porte possuem uma deposição de gordura mais tardia quando comparado com animais de menor porte.

Ainda com relação aos grupos genéticos, é observado que a capacidade destes em digerir alimentos, sobretudo a fibra, é diferenciada, implicando em diferenças de eficiência na utilização dos nutrientes em função do grupo genético. Assim, dependendo do tipo de dieta, seja mais volumosa ou mais concentrada, os grupos genéticos podem variar sua eficiência na conversão dos nutrientes alimentares em produto animal.

De uma forma geral, animais Bos taurus parecem apresentar melhor conversão alimentar do que os Bos indicus quando a dieta é à base de concentrados, enquanto que o grupo genético Bos indicus, devido à maior capacidade de digerir fibras que os microrganismos ruminais apresentam nesses animais, pode apresentar melhor conversão alimentar quando a dieta é a base de volumosos, sobretudo em sistemas de pastejo. Para Prado (2010), diferenças entre os grupos genéticos com relação a conversão alimentar podem estar associadas às exigências nutricionais.

Outro fator que também pode interferir no consumo e na conversão alimentar entre os grupos genéticos é o clima. Animais Bos indicus possuem uma maior adaptação ao clima tropical do que os Bos taurus, podendo interferir no comportamento alimentar entre esses grupos, principalmente em condições de alimentação a pasto.

\section{Conclusão}

Diante do exposto, fica evidente que as variáveis consumo, digestibilidade e conversão alimentar em bovinos de corte possuem um entendimento extremamente complexo e que 
apresentam muitas variações, geralmente em função do tipo de alimentação, do clima, dos grupos genéticos e dos sistemas de produção animal de uma forma geral. Contudo, é fundamental conhecer o que interfere mais significativamente essas características em cada propriedade e tomar medidas a fim de otimizálas, já que o máximo desempenho animal possui relação direta com a melhoria constante dessas características.

\section{Referências Bibliográficas}

Allen, M. S. 2000. Effects of diet on short-term regulation of feed intake by lactating dairy cattle. Journal of Dairy Science, 83, 15981624.

Andrade, D. K. B.; Ferreira, M.; Véras, A. S. C.; Wanderley, W. L.; Silva, L.; Carvalho, F.; Alves, K. S. \& Melo, W. 2002. Digestibilidade e absorção aparentes em vacas da raça Holandesa alimentadas com palma forrageira (Opuntia ficus-indica Mill) em substituição à silagem de sorgo (Sorghum bicolor (L.) Moench). Revista Brasileira de Zootecnia, 31, 2088-2097.

Baião, A. A. F.; ANDRADE, I.; Baião, E. A. M.; Baião, L. A.; Pérez, J. R. O.; Rezende, C.; Muniz, J. A.; Vieira, C. A. J. \& Bueno, G. D. 2005. Desempenho de novilhos mestiços Nelore suplementados em pastagem com diferentes níveis de concentrado no período seco do ano. Ciência e Agrotecnologia, 29, 1258-1264.

Bergamaschine, A. F.; Freitas, R. V. L.; Valério Filho, W. V.; Bastos, J. F. P.; Mello, S. Q. S. \& Campos, Z. R. 2011. Substituição do milho e farelo de algodão pelo milheto no concentrado da dieta de novilhos em confinamento. Revista Brasileira de Zootecnia, 40, 154-159.

Cabral, L. S.; Filho, S. d. C. V.; Detmann, E.; Malafaia, P. A. M.; Zervoudakis, J. T.; de Souza, A. L.; Veloso, R. G. \& Nunes, P. M. M. 2006. Consumo e digestibilidade dos nutrientes em bovinos alimentados com dietas à base de volumosos tropicais. Revista Brasileira de Zootecnia, 35, 2406-2412.

Costa, M. A. L.; Valadares Filho, S. d. C.; Paulino, M. F.; Valadares, R. F. D.; Cecon, P. R.; Paulino, P. V. R.; Moraes, E. \& Magalhães, K. A. 2005. Desempenho, digestibilidade e características de carcaça de novilhos zebuínos alimentados com dietas contendo diferentes níveis de concentrado. Revista Brasileira de Zootecnia, 34, 268-279.

Detmann, E.; Valadares Filho, S. C.; Pina, D. S.; Campos, J. M. S.; Paulino, M. S.; Oliveira, A. S. \& Silva, P. A. 2006. Estimação da digestibilidade do extrato etéreo em ruminantes a partir dos teores dietéticos: desenvolvimento de um modelo para condições brasileiras. Revista Brasileira de Zootecnia, 35, 1469-1478.

FAPRI. 2015. Food and Agricultural Policy Research Institute. In: Database, W. A. O. (ed.) Food and Agricultural Policy Research Institute. Iowa State University and University of Missouri-Columbia Ames, IA, USA.

Fernandes, H. J.; Paulino, M. F.; Martins, R. G. R.; Valadares Filho, S. d. C.; Torres, R. d. A.; Paiva, L. M. \& Moraes, G. 2004. Ganho de peso, conversão alimentar, ingestão diária de nutrientes e digestibilidade de garrotes não castrados de três grupos genéticos em recria e terminação. Revista Brasileira de Zootecnia, 33, 2403-2411.

Ferraz, J. B. S. \& Felício, P. E. 2010. Production systems - An example from Brazil. Meat Science, 84, 238-243.

Illius, A. W. \& Jessop, N. S. 1996. Metabolic constraints on voluntary intake in ruminants. Journal of Animal Science, 74, 3052-3062.

Mattos, L. M. E.; Andrade Ferreira, M.; Santos, D. C.; Andrade Lira, M.; Santos, M. V. F.; Batista, Â. M. V. \& Véras, A. S. C. 2000. Associação da palma forrageira (Opuntia ficus indica Mill) com diferentes fontes de fibra na alimentação de vacas 5/8 Holandês-Zebu em lactação. Revista Brasileira de Zootecnia, 29, 2128-2134.

McMeniman, J.; Defoor, P. \& Galyean, M. 2009. Evaluation of the National Research Council (1996) dry matter intake prediction equations and relationships between intake and performance by feedlot cattle. Journal of Animal Science, 87, 1138.

Mertens, D. R. 1987. Predicting intake and digestibility using mathematical models of ruminal function. Journal of Animal Science, 64, 1548-1558.

Mertens, D. R. 1994. Regulation of Forage Intake. In: Fahey, J. R. (ed.) Forage Quality, 
Evaluation, and Utilization. American Society of Agronomy, Madison, WI, USA.

Mertens, D. R. 1997. Creating a system for meeting the fiber requirements of dairy cows. Journal of Dairy Science, 80, 1463-1481.

Missio, R. L.; Brondani, I. L.; Filho, D. C. A.; da Silveira, M. F.; Freitas, L. S. \& Restle, J. 2010. Comportamento ingestivo de tourinhos terminados em confinamento, alimentados com diferentes níveis de concentrado na dieta. Revista Brasileira de Zootecnia, 39, 15711578.

Missio, R. L.; Brondani, I. L.; Freitas, L. S.; Sachet, R. H.; Silva, J. H. S. \& Restle, J. 2009. Desempenho e avaliação econômica da terminação de tourinhos em confinamento alimentados com diferentes níveis de concentrado na dieta. Revista Brasileira de Zootecnia, 38, 1309-1316.

Moreira, F. B.; Prado, I. N.; Cecato, U.; Wada, F. Y. \& Mizubuti, I. Y. 2004. Forage evaluation, chemical composition, and in vitro digestibility of continuously grazed star grass. Animal Feed Science and Technology, 113, 239-249.

NRC. 2000. Nutrient Requirements of Beef Cattle, 7th rev. edn. Natl. Acad. Press, Washington, DC, USA.

Olveira, E. A.; Sampaio, A. A. M.; Fernandes, A. R. M.; Henrique, W.; Oliveira, R. V. \& Ribeiro, G. M. 2009. Desempenho e características de carcaça de tourinhos Nelore e Canchim terminados em confinamento recebendo dietas com cana-de-açúcar e dois níveis de concentrado. Revista Brasileira de Zootecnia, 38, 2465-2472.

Paixão, M. L.; Valadares Filho, S.; Leão, M. I.; Valadares, R. F. D.; Paulino, M. F.; Marcondes, M. I.; Fonseca, M. A.; Silva, P. A. \& Pina, D. 2006. Uréia em dietas para bovinos: consumo, digestibilidade dos nutrientes, ganho de peso, características de carcaça e produção microbiana. Revista Brasileira de Zootecnia, 35, 2451-2460.

Pereira, D. H.; Pereira, O. G.; Valadares Filho, S. C.; Garcia, R.; Oliveira, A. P.; Martins, F. H. \& Viana, V. 2006. Consumo, digestibilidade dos nutrientes e desempenho de bovinos de corte recebendo silagem de sorgo (Sorghum bicolor (L.) Moench) e diferentes proporções de concentrado. Revista Brasileira de Zootecnia, 35, 282-291.

Pinto, A. P.; Marques, J. A.; Abrahão, J. J. S.; Nascimento, W. G.; Costa, M. A. T. \& Lugão, S. M. B. 2010. Comportamento e eficiência ingestiva de tourinhos mestiços confinados com três dietas diferentes. Archivos de Zootecnia, 59, 427-434.

Prado, I. N. 2010. Produção de bovinos de corte $e$ qualidade da carne. Eduem, Maringá, Paraná, Brasil.

Resende, F. D.; Queiroz, A. C.; Oliveira, J. V.; Pereira, J. C. \& Mâncio, A. B. 2001. Bovinos mestiços alimentados com diferentes proporções de volumoso: concentrado. 2. Efeito sobre a ingestão de nutrientes. Revista Brasileira de Zootecnia, 30, 270-279.

Russell, J. B.; O'connor, J. D.; Fox, D. G.; Van Soest, P. J. \& Sniffen, C. J. 1992. A net carbohydrate and protein system for evaluating cattle diets: I. Ruminal fermentation. Journal of Animal Science, 70, 3551-3561.

Silva, F. F.; Valadares Filho, S. C.; Ítavo, L. C. V.; Veloso, C. M.; Paulino, M. F.; Valadares, R. F. D.; Cecon, P. C.; Silva, P. A. \& Galvão, R. M. 2002. Consumo, desempenho, características de carcaça e biometria do trato gastrintestinal e dos órgãos internos de novilhos Nelore recebendo dietas com diferentes níveis de concentrado e proteína. Revista Brasileira de Zootecnia, 31, 18491864.

Souza, S.; Ítavo, L. C. V.; Rímoli, J.; Ítavo, C. \& Dias, A. M. 2007. Comportamento ingestivo diurno de bovinos em confinamento e em pastagens. Archivos de zootecnia, 56, 67-70.

Valadares Filho, S. C. 2006. Tabelas brasileiras de composição de alimentos para bovinos. UFV, Viçosa.

Van Soest, P. J. 1994. Nutritional ecology of the ruminant. Cornell University Press, Ithaca, NY, USA.

Zeoula, L. M.; Fereli, F.; Prado, I. N.; Geron, L. J. V.; Caldas Neto, S. F.; Prado, O. P. P. \& Maeda, E. M. 2006. Digestibilidade e balanço de nitrogênio de rações com diferentes teores de proteína degradável no rúmen e milho moído como fonte de amido em ovinos. Revista Brasileira de Zootecnia, 35, 21792186. 
Zeoula, L. M.; Prado, I. N.; Dian, P. H. M.; License information: This is an open-access Geron, L. J. V.; Caldas Neto, S. F.; Maeda, E. article distributed under the terms of the Creative M.; Peron, P. D. P.; Marques, J. A. \& Falcão, Commons Attribution License, which permits A. J. S. 2002. Recuperação fecal de unrestricted use, distribution, and reproduction in indicadores internos avaliados em ruminantes. any medium, provided the original work is Revista Brasileira de Zootecnia, 31, 1865- properly cited 1874.

Recebido em Outubro 2, 2014

Aceito em Fevereiro 3, 2015 